\title{
Yangzhou Cuisine Tourism Resource Development: Situation and Recommendations for Improvement
}

\author{
Yi Zhang
}

\begin{abstract}
Chinese culinary arts have a long history, and upon generations of refinement, have ingrained themselves as part of Chinese culture. Yangzhou is among the most renowned tourist cities in China. With over 2,500 years of history and abundant tourism resources, it attracts a large number of tourists every year. Yangzhou cuisine, thanks to its variety, elaborate preparation, and well-established history, has become an important component of the local tourism resources. This paper is prepared based on a market research conducted and field survey method for the Yangzhou cuisine tourism resources. It identifies certain issues that are adversely affecting the tourism industry. They include lack of creative ideas and initiatives in brand creation and promotion, limited marketing tools, and low-quality services among practitioners in the industry. Recommendations are then made to better capitalize on Yangzhou cuisine as a tourism resource, including focusing more on product design, transforming marketing strategies, fostering stronger brand awareness, and improving service quality.
\end{abstract}

Index Terms - Cuisine tourism, recommendations, Yangzhou

\section{INTRODUCTION}

China abounds in resources and products. Its culinary arts are extensive, elaborate, and sophisticated, highlighting the esteem the Chinese place in their food. The eight well-established cuisines in China all have distinct features. Yangzhou is among the originating places of the Huaiyang Cuisine, one of these eight well-recognized cuisines. Yangzhou's long history as a city can be traced back to as early as 486 BC. It is also a blessed place with outstanding people. Yangzhou is acclaimed as "a renowned city in the Southeast Huai Region and a gorgeous place beside the Zhuxi Arbor." In the spring of the eighth year during the Qingli Era of the Song Dynasty, a great ancient Chinese writer $\mathrm{Ou}$ Yangxiu often held feasts in the Pingshantang mansion with his guests, which brought great fame to Yangzhou cuisine. The Yangzhou Chronicle compiled during the Wanli Era of the Ming Dynasty points out that "Yangzhou cuisine, with its luxury, refined preparation techniques, and variety, trumpeted itself in the region south of the Yangtze River." This highlights the extravagance, finesse, and wide range of recipes of the Yangzhou culinary arts at that time. Yangzhou cuisine culminated during the Qing Dynasty by virtue of praise among intellectuals. Since China's reform and opening to the outside world in the early 1980s, most dishes served at Chinese state banquets belong to Huaiyang cuisine. Thanks to

Manuscript received April 10, 2019; revised May 1, 2019.

Yi Zhang is with Department of Tourism management of Yancheng Teachers University, Jiangsu, China (e-mail: merryzhang0805@163.com). the elaborate cutting, exquisite carving, simple but authentic materials, and the slightly sweet but less salty taste, this cuisine has also become the favorite of many ordinary peoples.

The continuous improvement of living standard in China has brought about new trends in the tourism industry. Tourists are not content with only seeing the scenic attractions; they also hope to experience the local culture, traditions, and customs, and in so doing, seek enjoyment and satisfaction that they have never experienced before. The catering sector in Yangzhou has been faring better and better since China's reform and opening to the outside world. Statistical data indicate that the total revenue of the catering industry in 2015 amounted to RMB16.86 billion, an increase of $14.7 \%$ from the previous year. Ten catering businesses that were randomly chosen and closely observed grossed RMB 310 million over the same period, an $8 \%$ increase over the previous year. Yangzhou's catering sector keeps the momentum of high growth. Meanwhile, the City of Yangzhou has rolled out a variety of measures to further encourage growth of traditional, time-honored brands in the industry. The measures include issuing the Report on Growth of Time-Honored Brands in Yangzhou, formulating the first set of criteria to facilitate the selection of "Time-Honored Brands in Yangzhou," and developing the Policy to Support Time-Honored Brands in Yangzhou. The initiatives have had positive effects on the growth of the traditional, well-established brands in Yangzhou, bringing in flocks of customers and abundant opportunities for the growth of catering businesses. These brands include the "Sanchun" series of teahouses, namely the Fuchun Teahouse, Yechun Teahouse, and Gonghechun Teahouse; the Shiweitian Restaurant; and Sanhe Simei, which is well known for its traditional Chinese pickles. Meanwhile, a number of activities, such as the Yangzhou International Cuisine Festival, Yangzhou Across-the-Straight Vegetarian Food Festival, Guazhou Fresh-Water Food Festival, Spiral Shell Food and Sightseeing Festival, Shaobo Lake Crawfish and Tourism Festival, Chinese Double-Yolk Duck Egg Festival, and the Gaoyou Tourism and Cuisine Festival, have helped promote the Yangzhou Cuisine. Through a series of food festival activities, individuals, organizations and countries can be linked together. The beauty of food is that people are always happy together through food exchange. It is often said that the fate of a nation depends largely on how its citizens balance their nutritious diet. The flow of people drives the spread of food, which in turn conveys culture and helps people better understand different traditional cultures, values and world views.

In-depth research of the cuisine resources in Yangzhou will help increase Yangzhou's appeal as a tourist destination. The 
cuisine provides tourists with opportunities to not only enjoy delicious food, but also appreciate the local history, culture, and traditions, thereby enriching their experience. This type of study will help with the growth of the catering industry and heighten the value of the Yangzhou cuisine as an economic resource.

\section{LITERATURE REVIEW}

\section{A. Research Findings Outside China}

Given that catering play a critical role in the tourism industry, many scholars have studied the importance of this economic sector. Ashleigh Ellis, Eerang Park , Sangkyun Kim and IanYeoman (2018) [1] believed food tourism or food and tourism has emerged as a major theme for recent tourism research. Senagel et al. (2015) [2] believed that cuisine has become a main reason to travel for some tourists. Hjalager and Corigliano (2000) [3] believed that Italy's tourism growth relied on the local cuisine and wine culture. Getz and Brown (2006) [4] believed that catering at tourist destinations have a positive relationship with tourists' tendency to visit.

Many scholars find some important influencial factors on cuisine tourism. Ashleigh Ellis, Eerang Park , Sangkyun Kim and IanYeoman (2018) [1] believed that food tourism is dominated by five themes: motivation, culture, authenticity, management and marketing, and destination orientation. Pornpisanu, Promsivapallop, Prathana, Kannaovakun (2019) [5] revealed five destination food image factors comprising restaurant service, food taste, health and hygiene, variety and eating manners, and unique cultural experience. In summary, cuisine is closely related to tourism activities and is a major factor in attracting tourists.

Many scholars pay more attantion on interaction. Mohd HairiJalis, Deborah Che (2014) [6]believed that helping tourists to anticipate the type of food experience is very important when travelling in Malaysia and the Malaysian Government is particular in the details selected for images of and narrative on the local cuisine. Sonja SibilaLebe (2015) [7] believed that tourists also have the possibility to participate in cooking courses on local gastronomy, enjoy massages with use of local spices, or can acquaint themselves with the use of spices and herbs in the local traditional medicine. MarcStierand, JoachimSandt (2007) [8] believed that there is a significant need to reduce back office activities so that interaction with the customer or customer-facing processes can be increased. Lawrence, W.LanaWei, WenWubYu, TingLee (2012) [9] believed that one promising means to innovate the local food is to incorporate essential features of renowned international cuisine into the local gastronomy to serve as a destination marketing enabler.

\section{B. Research Findings in China}

Chinese literature on this topic mainly focuses on studies of recipes and the culinary arts. Many scholars have studied the strategies on cuisine tourism. Using Chengdu as an example, Xiong (2011) [10] proposed to hold more tourism and cultural festivals, while also emphasizing that tourists should be encouraged to participate in the activities related to local cuisine in Chengdu. Focusing on the local dishes, Niu (2012) [11] used tourists satisfaction to formulate a frame for analysis and made recommendations for improving the cuisine in Sha County. Li (2010) [12] insisted that cuisine tourism should follow a green path, stick to green development principles, and develop green cuisine products. Bai (2014) [13] analyzed the data collected through surveys and proposed measures to address some issues in cuisine tourism development. Wang (2013) [14] looked into the current situation of the catering industry in Qingdao and made recommendations accordingly. Wu (2010) [15] proposed strategies regarding cuisine tourism from the perspective of leisure economy. Yue (2010) [16] suggested that tourists to Xi'an favor the local snacks. Zhang (2012) [17] proposed a vision for Xinjiang's cuisine tourism. Li (2008) [18 ] believed that there are many ways to develop Yangzhou cuisine, they are setting up the brand consciousness, shaping the characteristic image of Yangzhou cuisine, using the strong media to publicize Huaiyang cuisine, encouraging the development of cooking education research and innovation of Huaiyang cuisine.

In China, cuisine has not received the attention it deserves as a tourism resource. Therefore, regarding the development of cuisine as a tourism resource, only some suggestions are available.

\section{METHOdOLOGY AND RESEARCH SAMPLE}

\section{A. Methodology}

This paper provides a summary and analysis of Yangzhou's cuisine tourism through literature review as well as data collection and analysis. Data collected through a survey is analyzed using MS Excel to help understand tourists' recognition of Yangzhou's cuisine as a tourism resource. At the same time, through the field survey method, to understand the general situation of Yangzhou cuisine and existing problems. The paper then proposes recommendations to address issues identified during the research on the development of cuisine tourism in Yangzhou.

\section{B. Research Sample}

Attractions with high concentration of visitors, such as the Slender West Lake and Dongguan Street, and dining locations close to them, were selected venues for the survey. The survey took place between October and November of 2018. A total of 200 questionnaires were distributed and 190 valid questionnaires were received, with a valid rate of $95 \%$.

The respondents of this questionnaire are all non-local tourists. Female accounts for $59 \%$ and male accounts for $41 \%$. Ages range from 18 to 50. Among the respondents, 44\% come from Yangzhou's core tourist source market. This is basically consistent with the main tourist groups in Yangzhou tourism market. The distribution of tourist sources is in good agreement with the market positioning of tourist sources in Yangzhou. Cronbach $\alpha$ is a reliability coefficient which is the most commonly used reliability coefficient, the formula is: $\alpha=(k /(k-1))^{*}\left(1-\left(\sum S i^{\wedge} 2\right) / S T^{\wedge} 2\right)$. Cronbach's alpha coefficient was 0.755 . Therefore, this survey has a representativeness and 
credibility.

TABLE I: DEMOGRAPHICS OF RESPONDENTS

\begin{tabular}{|c|c|c|c|}
\hline \multicolumn{2}{|c|}{ Respondent Information } & $\begin{array}{l}\text { Number } \\
\text { of } \\
\text { Responde } \\
\text { nts } \\
\end{array}$ & Percentage \\
\hline \multirow{2}{*}{ Gender } & Male & 77 & 41 \\
\hline & Female & 113 & 59 \\
\hline \multirow{4}{*}{ Age } & Under 18 & 40 & 21 \\
\hline & $18-35$ & 83 & 44 \\
\hline & $35-50$ & 50 & 26 \\
\hline & Above 50 & 17 & 9 \\
\hline \multirow{4}{*}{ Education } & $\begin{array}{c}\text { Senior High } \\
\text { School and } \\
\text { Under }\end{array}$ & 45 & 24 \\
\hline & College & 53 & 28 \\
\hline & Undergraduate & 40 & 21 \\
\hline & $\begin{array}{c}\text { Post-graduate } \\
\text { and Higher }\end{array}$ & 52 & 27 \\
\hline \multirow{3}{*}{$\begin{array}{l}\text { Region of } \\
\text { Residence }\end{array}$} & $\begin{array}{c}\text { Shanghai, } \\
\text { Jiangsu, Anhui, } \\
\text { Shandong, } \\
\text { Zhejiang }\end{array}$ & 83 & 44 \\
\hline & $\begin{array}{c}\text { Beijing, } \\
\text { Tianjin, } \\
\text { Guangdong, } \\
\text { Hebei, Henan }\end{array}$ & 62 & 33 \\
\hline & $\begin{array}{l}\text { Other regions in } \\
\text { China }\end{array}$ & 45 & 23 \\
\hline
\end{tabular}

\section{RESULTS AND DISCUSSION}

A. Analysis on Recognition of Yangzhou Cuisine Tourism Products

\section{1) recognition of traditional brands}

A component of the research is to ascertain tourists' recognition of Yangzhou's traditional, time-honored cuisine brands. Some representative brands were selected for this purpose. The result of the survey indicates that $40 \%$ of tourists knew little about the traditional, well-established brands selected for the study. The most recognized was the pickle brand Sanhe Simei Pickles, which scored a recognition rate of $21 \%$, followed by the Fuchun Teahouse and Yechun Teahouse, which scored $20 \%$ and $12 \%$, respectively. The brands Daqilinge and Gonghechun were much less known to the visitors.

\section{2) Analysis on recognition of cuisine streets}

In terms of recognition of cuisine streets in Yangzhou, 52\% of the tourists somewhat knew about the Dongguan Street; $37 \%$ of the tourists knew nothing about the Siwangting Road, Wangyue Road, or Huaihai Road. Tourists knew very little about the rest of the cuisine streets.

\section{3) Analysis on recognition of intangible cultural heritage}

Yangzhou has bountiful intangible cultural heritage, including the cooking and preparation techniques for lotus foods, pickles, the fried rice, Gaoyou salty duck eggs, and Fuchun pastries. The survey indicates that $41 \%$ of the tourists were unaware of the existence of intangible cultural heritage in Yangzhou cuisine. This suggests that most venues that serve Yangzhou cuisine are still limited to providing the products, with little effort being invested in introducing, demonstrating, and promoting the cuisine as a tourism resource. As a result, Yangzhou cuisine is still a hidden treasure to be discovered.

\section{B. Tourist Preference Analysis \\ 1) Information sources}

The survey indicates that $45 \%$ of the tourists learned about Huaiyang cuisine through the internet. This is followed by television and communication with friends and relatives. Few tourists learned about Huaiyang cuisine through books, newspapers, periodicals, or other channels. This is closely related to peoples' reading habit and also an indication that the new media, including the internet, are preferred by the public to the traditional media.

\section{2) Venues for dinning}

The survey reveals that traditional-brand restaurants were tourists' favorite places for dinning. The other venues that tourists chose to dine at, in the order of preference, include the cuisine streets; local snack stalls along the tour routes; restaurants close to attractions; and lastly, high-end star hotels. Traditional-brand restaurants in Yangzhou have good reputation and represent a time-honored heritage. The cuisine streets provide opportunities for tourists to enjoy the unique local foods. The local snack stalls along the tour routes cater to the taste of most tourists. The advantage of restaurants close to attractions is their convenience. High-end star hotels provide high-quality, high-standard foods. These foods, however, lack the features of local cuisine and cannot meet the need of tourists who hope to try authentic Yangzhou cuisine. As such, most tourists preferred dinning at traditional-brand restaurants and cuisine streets, which embodies Yangzhou's culture and tradition. This, to some extent, reflects tourists' pursuit for high-quality tourism nowadays.

\section{3) Factors affecting choice for dinning}

The survey indicates that $41 \%$ of tourists regarded the quality of service as the most important consideration in choosing a place for dinning. This is followed by the price, which scored $33 \%$. The rest of the factors considered by tourists include facilities, location, and others, scoring $5 \%$, $17 \%$, and $4 \%$, respectively. With the improvement of living standards, tourists place more emphasis on the quality of service. The demeanor of the practitioners, promptness in serving, and cleanness of the facilities all contribute to the quality of service.

\section{4) Shopping for cuisine products}

The survey indicates that $57 \%$ of tourists preferred buying cuisine products that are easy to carry along. Several factors made people reluctant to buy cuisine-related products, including inconvenience in carrying them during traveling (for example, the Three Knives of Yangzhou are restricted by public transportation regulations) or lack of creative ideas in the products. 


\section{3. Problems}

\section{1) Lack of creative ideas for products}

Through the field survey we found that specializing in Huaiyang cuisine characteristic restaurants are often hard to find in Yangzhou. The local dishes you want to taste are always stuck in a few single dishes, lacking innovation. There is a lack of creative ideas in Yangzhou's cuisine tourism products. This is reflected in three areas aspects: 1 . Insufficient exploration and integration of cuisine tourism resources led to limited cuisine tourism routes. 2.Lack of innovation in products led to serious homogenization. 3. There are limited products for tourists to experience in person. Yangzhou cuisine tourism products need continuous innovation and improvement so as to keep abreast with the times and meet tourists' need in seeking new and creative products.

\section{2) Lack of Awareness in Brand Promotion}

The survey finds that many tourists knew of Yangzhou cuisine, an indication that the local brands have some reputation. However, the tourists did not have in-dept knowledge of the brands. This means that the potential of the local brands has yet to be tapped into due to the lack of awareness among practitioners in the industry. We also learn from the survey that, despite the large number of traditional brands in Yangzhou, many tourists were still unaware of them.

\section{3) Marketing strategies need improvement}

The survey result indicates that today's tourists mainly rely on the Internet to look up for tourism information. The 21th century is the era of Internet and science. Traditional media, such as books, television, periodicals, and newspapers do not suffice in meeting peoples' needs. The implication for Yangzhou cuisine is that its marketing strategies need innovative ideas and continuous improvement.

\section{4) Low service quality among practitioners}

Both the tourism and catering industries are service-oriented. Well-cultivated practitioners are critical to their success. Some cuisine businesses in Yangzhou are operated and managed by the owners themselves, who have never received professional training and lack the skills in managing a business. Often they hire temporary workers and provide minimal instructions and training. As a result, during peak tourism seasons when there is a large number of tourists, the workers often make mistakes and the restaurants do not have sufficient supply, which leads to long waiting time. Also, some service personnel cannot speak standard mandarin Chinese, creating issues in communication with tourists. Therefore, training is needed to improve practitioners' knowledge, skills and demeanor.

\section{COUNTERMEASURES AND SUGGESTIONS}

\section{A. Focus on Design and Lauch Innovative Tourism Products}

Yangzhou cuisine needs continuous improvement with the times. It should focus on personality, practicality, exquisiteness, and convenience, with a goal to create novel, eye-catching tourism products so as to satisfy the needs for new, unique, and changing things in the tourism market. The cuisine resources can be utilized to develop tour routes such as cuisine and health keeping tours, and cuisine and exploration tours. Alternatively, themed tour routes can be tailored to different groups. For instance, a themed tour route entitled The Cuisine Journey with Best Girl Friend can be designed for female tourists, and A Romantic Cuisine Journey can be designed for lovers. To enable tourists to better appreciate the features that Yangzhou Cuisine has to offer, products can be designed to aim at a whole family or lovers. It is suggested that the Chinese Museum of Huaiyang Cuisine take advantage of the technologies in electronics, lights, and acoustics to make vivid presentations to visitors about the preparing process and skills of Huaiyang cuisine. Governments may choose to hold contests to engage the general public in participating in designs of cuisine tourism routes and innovative cuisine tourism products. The ideas collected through these contests will be used as input to create innovate cuisine tourism products, thereby transforming Yangzhou cuisine into exquisite tourism products that are easy to bring along.

\section{B. Transform Marking Strategies and Develop New Media-Based Marketing Network}

With the rapid development of the Internet technology, the new media have had considerable impact on the traditional media. To keep abreast of the times and adapt to the market needs, there is a need to develop a new media marketing system that is mainly based on Internet media as marketing platforms. A tourism database for Yangzhou cuisine can be further developed based on this marketing system. Internet-based marking modes are favored by many people. Product placement and word-of-mouth marketing can help increase efficiency in promotion and improve effects of marketing. Hot news stories and celebrities can help attract tourists' attention. Finally, the government is a good place to seek help when it comes to developing tourism databases for Yangzhou.

\section{Foster Brand Awareness and Strengthen Brand Promotion}

Yangzhou cuisine is both a tourism product and a tourism resource. Marketing of Yangzhou cuisine should focus on fostering awareness of the brands as well as brand promotion to increase recognition by tourists. The traditional brands should be used as standards in conducting in-depth studies of the history and cultural values of Yangzhou cuisine and in designing commercials to promote the industry. Yangzhou cuisine should be regarded as a name card for local tourism and integrated into Yangzhou's tourism brand. Promotion of the Yangzhou cuisine brands should be a joint effort between the government and businesses. Strategies for brand promotion need to be tailored to different market demands and aim at different tourist groups. A comprehensive plan that integrates all strategies for brand promotion, including public relations, advising, and media should be adopted. This plan will be supported by multiple communication channels, such as word of mouth, the Internet, news stories, and a combination of media, to maximize the effect of promotion. 


\section{Improve Quality of Service and Streamline Business Management}

The survey indicates that $41 \%$ of tourists would consider the quality of service as the most important factor in choosing a place for dinning. It follows that the quality of service is of paramount importance to tourists. Businesses in Yangzhou's catering industry should improve employee management, uphold the principle of "people first", and strengthen training. Managers can also use performance measurement to motivate practitioners.

\section{CONCLUSION}

There is a saying, "go enjoy Yangzhou during the spring when the flowers are blossoming." Yangzhou's bounty of tourism resources and ancient history bestow the city with many delicious foods that have earned endless praise. Yangzhou cuisine has considerate potential for development and growth. Appropriate development of the cuisine will benefit the tourism industry. Through a questionnaire survey, this paper looks into the current situation and tourists' demand in Yangzhou's cuisine tourism market and proposes recommendations for further tapping into this resource. Due to the length of the paper and the sample size of the survey, the conclusions of the paper might have some limitations. The specific project development methods and operation modes will be a topic for future studies.

\section{REFERENCES}

[1] A. Ellis, E. Park, S. K. Kim, and I. Yeoman, "What is Food tourism?" Tourism Management, vol. 68, pp. 250-263, October 2018.

[2] T. Sengel, A. Karagoz, G. Cetin et al., "Tourists'approach to local food," Social and Behavioral Sciences, vol. 195, pp. 429-437, July 2015.

[3] A. Hjalager and M. Corigliano, "Food for tourism-determinants of image," International Journal of Tourism Reasech, vol. 2, pp. 281-293, April 2000.

[4] D. Getz and G. Brown, "Critical success factors for wine tourism regions: demand analysis," Tourism Management, vol. 27, pp. 146-158, February 2006.

[5] P. Promsivapallop and Prathana, Kannaovakun, "Destination food image dimensions and their effects on food preference and consumption," Journal of Destination Marketing and Management, vol. 11, pp. 89-100, March 2019.
[6] M. H. Jalis and D. Che, "Utilising local cuisine to market Malaysia as a tourist destination," Procedia Social and Behavioral Sciences, vol. 144, pp. 102-1120, August 2014.

[7] S, S. Lebe, "Spices and tourism: Destinations, attractions, and cuisines," Annals of T ourism Research, vol. 54, pp. 232-233, September 2015

[8] M. Stierd and J. Sandt, "Organising haute-cuisine service processes: A case study," Journal of Hospitality and Tourism Management, vol. 14, pp. 24-36, April 2007.

[9] W. Lawrence, L. Wei, W. W. Yu, and T. Lee, "Promoting food tourism with Kansei cuisine design," Procedia - Social and Behavioral Sciences, vol. 40, pp. 609-615, March 2012.

[10] S. Xiong, "Development of Chengdu cuisine as tourism resource," Master Dissertation, Dept. Tourism., Shandong University., Shandong, China, 2011

[11] H. Niu, "Research on cuisine tourism development from tourists' perspective--A Case Study of Shaxian Local Dishes," Master dissertation, Dept. Tourism., Fujian Normal University, Fujian, 2012.

[12] X. Li, "Development of green cuisine tourism - A case study of Dalian's practices," Economic Research Guide, vol. 24, pp. 129-130, Augest 2018.

[13] S. Bai, "Research on cuisine tourism development in Kaifeng," Master Dissertation, Dept.Tourism., Henan University., Henan, China, 2014.

[14] J. A. Wang, "Study on development of cuisine culture and tourism in Qingdao," Master Dissertation, Dept. Tourism, Shangdong University., Shangdong, China, 2013.

[15] X. Wu, "Strategies for China's cuisine tourism development - From a leisure economy perspective," China Business and Trade, vol. 19, pp. 141-142, October 2010.

[16] D. Yue and Y. Yang, "An empirical analysis of domestic tourists' preferences in Xi'an," Journal of Xi'an University of Arts \& Science(Natural Science Edition), vol. 2, pp. 116-119, April 2010.

[17] Y. Zhang, "Study of Xinjiang cuisine tourism development," Master Dissertation, Dept. Tourism, Xinjiang Normal University, Xinjiang, China, 2012

[18] C Hua and R. Li, "Vigorously develop Huaiyang cuisine to create Yangzhou cuisine characteristics," Market Modernization, vol. 548, pp. 125-126, August 2008.

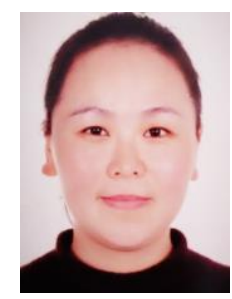

Yi Zhang was born in Ningguo, Anhui, China. She is a lecturer at the Department of Tourism management of Yancheng Teachers University since 2006. She got the master degeree in tourism Management, guilin University of Technology, Guilin, Guangxi, P. R. China. 